\title{
MODERN AIRCRAFT ELECTRONIC POWER CONVERTERS
}

\author{
Martin SCHRÖTTER, Martin MATIS, Jakub LEŠKO \\ Department of avionics, Faculty of aeronautics, Technical university of Kosice, Rampová 7, Košice. \\ *Corresponding author. E-mail: martin.schrotter@tuke.sk
}

\begin{abstract}
The article points out to changes in on-board aircraft power converters, which are necessary due to weight reduction and improvement of reliability and maintenance. The paper presents the evolution from old rotary converters to modern solid state converters and describes their advantages. There is also the mention about electro-magnetic interference (EMI), which is introduce during the conversion and how could it be reduced for different types of converters. The operational principle of various power inverters is simulated in MATLAB to figure out different output waveforms quality which could be reached by such a conversion.
\end{abstract}

Keywords: solid state power electronic converter; more electric aircraft

\section{INTRODUCTION}

The aircraft electrical power systems were evolving from the beginning of aviation. Their use has enabled to implement new appliances which contributed to increase the comfort and safety on-board the aircraft. However, the extended use of electrical components required not only the implementation of stronger electrical system but also the change of DC electrical system into the AC electrical system. Such changes also required the use of different types of power converters, namely: AC to AC, AC to $\mathrm{DC}, \mathrm{DC}$ to $\mathrm{AC}$ and DC to DC converter [1,2]. In that time, there were used mostly:

- rotary converters to change DC power into AC power (inverters) and to change frequency of $\mathrm{AC}$ power (frequency converters),

- transformers to convert AC power into another value of $\mathrm{AC}$ power,

- motor-generators to convert low voltage DC into high voltage DC,

- vacuum tube to convert AC power to DC power (rectifier).

However, many of these converters were bulky, heavy and required heavy maintenance due to rotating parts and also their efficiency was low. The low efficiency means the high heat dissipation which could results in the deterioration of the wires' insulation material or in the worst case it could lead to the fire. Also the power generators have to be rated to higher power amounts to overcome these losses.

\section{POWER CONCEPT OF THE TRADITIONAL AIRCRAFT}

There is a description of traditional aircraft power concept in this chapter. Each aircraft engine produces not only thrust power but also non-thrust powers. These are further divided into:

- mechanical power

- hydraulic power

- pneumatic power

- electrical power.

Under the term traditional concept of aircraft in terms of powers it is meant the aircraft which non-thrust powers are mainly in form of pneumatic and hydraulic power. The respective loads for given non-thrust powers are denoted in Tab.1. The ratio of non-thrust powers is only approximate. The 
exact values will be different for each type of the aircraft. The generated power outputs for traditional aircraft are in the range from $45 \mathrm{kVA}$ per generator for small aircraft up to $120 \mathrm{kVA}$ per generator for large commercial aircraft. Overall output of all generators was up to $500 \mathrm{kVA}$ for the biggest airplanes.

Traditional large aircraft utilise centralised power distribution system. Generated voltage is three phase $115 / 200 \mathrm{~V}$-AC with constant frequency $-400 \mathrm{~Hz}$ and is used to supply all heavy loads. However, some loads (avionics and essential loads) require $28 \mathrm{~V}-\mathrm{DC}$.

Table 1 The utilisation of non-thrust powers on-board the traditional aircraft [3]

\begin{tabular}{|l|l|l|}
\hline Non-thrust powers: & Percentage of powers & Loads \\
\hline Mechanical & $5 \%$ & Fuel and oil pumps \\
\hline Electrical & $10 \%$ & $\begin{array}{l}\text { Electrical systems of engines, cabin systems, } \\
\text { fire-protection systems, lights and signaling } \\
\text { systems, avionic systems - instruments, } \\
\text { navigation and communication systems, data } \\
\text { recording systems }\end{array}$ \\
\hline Hydraulic & $15 \%$ & $\begin{array}{l}\text { Actuators of control surfaces, landing gear, } \\
\text { brakes, thrust reverser, cargo doors actuators }\end{array}$ \\
\hline Pneumatic & $70 \%$ & $\begin{array}{l}\text { Air conditioning and pressurization system, } \\
\text { anti-icing and de-icing systems, pneumatic } \\
\text { actuators }\end{array}$ \\
\hline
\end{tabular}

\section{POWER CONCEPT OF THE MORE ELECTRIC AIRCRAFT}

The concept of More electric aircraft (MEA) appeared for the first time after the Second World War. In those days emerged the request for fast public transportation over a long distances. The reasonable solution was found in the aviation industry. The first spacious aircraft were introduced which could easily transport many passengers. But long haul flights also required some means for storage the meals in a cold place and also the possibility to heat it. This and many other systems used in those aircraft required electrical power for operation.

In modern days the concept of MEA means that there is the dominant use of electrical power over other non-thrust powers (usually more than 50\%). The respective loads for given non-thrust powers are denoted in Tab. 2. The typical representative of this category is Boeing B787, Airbus A350 and LockHeed Martin F35. The generated power outputs for MEA are in the range from $100 \mathrm{kVA}$ up to $250 \mathrm{kVA}$ per generator for large commercial aircraft. Overall output of all generators is up to 1500 kVA [4].

Such modern aircraft use different type of distribution system - decentralised power distribution system. Generated voltage is three phase $230 / 400 \mathrm{~V}$-AC with variable frequency $(320-860 \mathrm{~Hz})$ [5] and is used to supply only heavy resistive loads such as anti-icing system or $\pm 270 \mathrm{~V}-\mathrm{DC}$. However, some loads still require $28 \mathrm{~V}$-DC and 115/200 V-AC with frequency $400 \mathrm{~Hz}$. From that reason the modern aircraft need to use several power converters. Source with variable frequency enables not to use Constant speed drive or Integrated drive generator unit and so reduces power losses. 
Table 2 The utilisation of non-thrust powers on-board the MEA [3]

\begin{tabular}{|l|l|l|}
\hline Non-thrust powers: & Percentage of powers & Loads \\
\hline Mechanical & $5 \%$ & Fuel and oil pumps \\
\hline Electrical & $85 \%$ & $\begin{array}{l}\text { Electrical systems of engines, cabin systems, } \\
\text { fire-protection systems, lights and signaling } \\
\text { systems, avionic systems - instruments, } \\
\text { navigation and communication systems, data } \\
\text { recording systems, Electro mechanical } \\
\text { actuators, Electro hydrostatic actuators, } \\
\text { steering and braking, cargo doors, thrust } \\
\text { reverser, Air pressurization, anti-icing } \\
\text { systems }\end{array}$ \\
\hline Hydraulic & $5 \%$ & $\begin{array}{l}\text { Some actuators of control surfaces, landing } \\
\text { gear extension, retraction }\end{array}$ \\
\hline Pneumatic & $5 \%$ & Air conditioning system, pneumatic actuators \\
\hline
\end{tabular}

\section{MODERN POWER CONVERTERS}

The necessity to convert big amounts of electrical energy requires the use of converters with very good efficiency to prevent excessive heat dissipation. From such reasons all modern power converters are based on the solid state technology. They are denoted as Solid state power converters (SSPC). The key components inside the SSPC are power switches with very high switching frequency: $20-40 \mathrm{kHz}$ [6,7]. Such a frequency is necessary to produce smooth voltage and current waveforms which are necessary for sensitive avionics systems. On the other hand, this switching frequency is a source for electro-magnetic interference (EMI). Switches suitable to perform such a rapid switching are MOSFETs and IGBTs.

Previously mentioned rotary inverters were replaced mostly with some modification of H-Bridge converter. Voltage input is in the range $26-30 \mathrm{~V}-\mathrm{DC}$ and voltage output is in two levels: output_1 is $115 \mathrm{~V}$-AC and voltage output_2 is $26 \mathrm{~V}$-AC with accuracy $\pm 5 \%$ and frequency $400 \mathrm{~Hz}$ with accuracy $\pm 1 \%$. Such converters are resistant to all forms of power factor.

Old style diode bridge rectifiers were replaced with Pulse width modulation (PWM) buck-rectifiers with efficiency $91-93 \%$ [8].

The traditional bipolar junction transistors (BJT) for DC to DC conversion were replaced with Buck/Boost converters with field effect transistors (FET). These enable also bidirectional conversion.

\section{INVERTER SWITCHING SIMULATION}

The switching simulation of three types of inverters was performed in Simscape ${ }^{\mathrm{TM}}$ within the

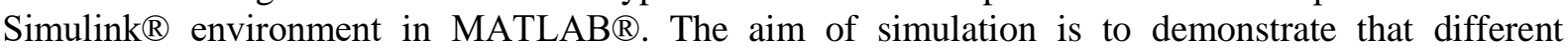
controlling methods of power switches strongly affect the output waveform, which is the cause for EMI. For our experiment we have created three types of power inverters, based on half H-bridge configuration (Fig. 1), H-Bridge configuration (Fig. 2) and double H-Bridge configuration (Fig. 3). 


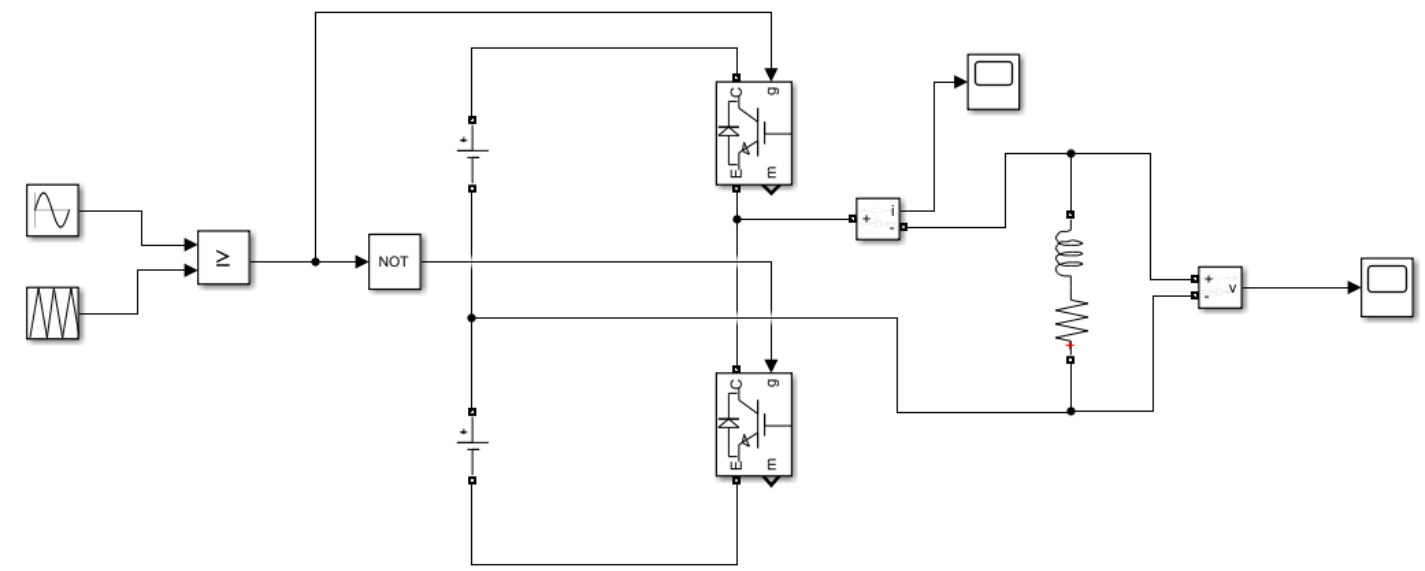

Figure 1 Inverter number 1

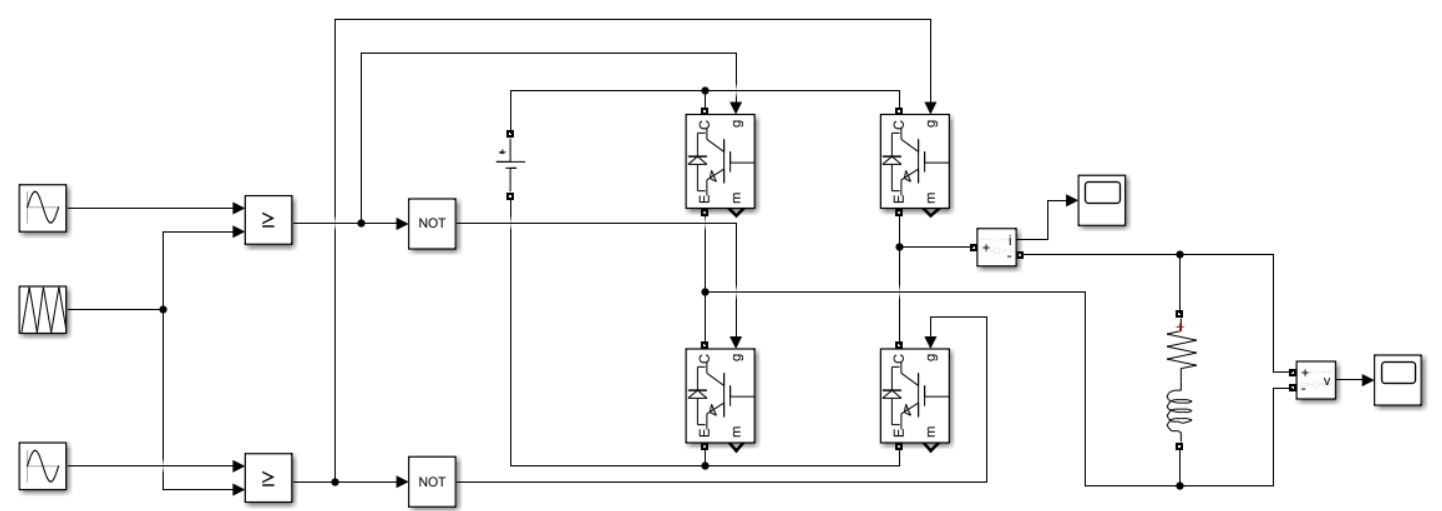

Figure 2 Inverter number 2

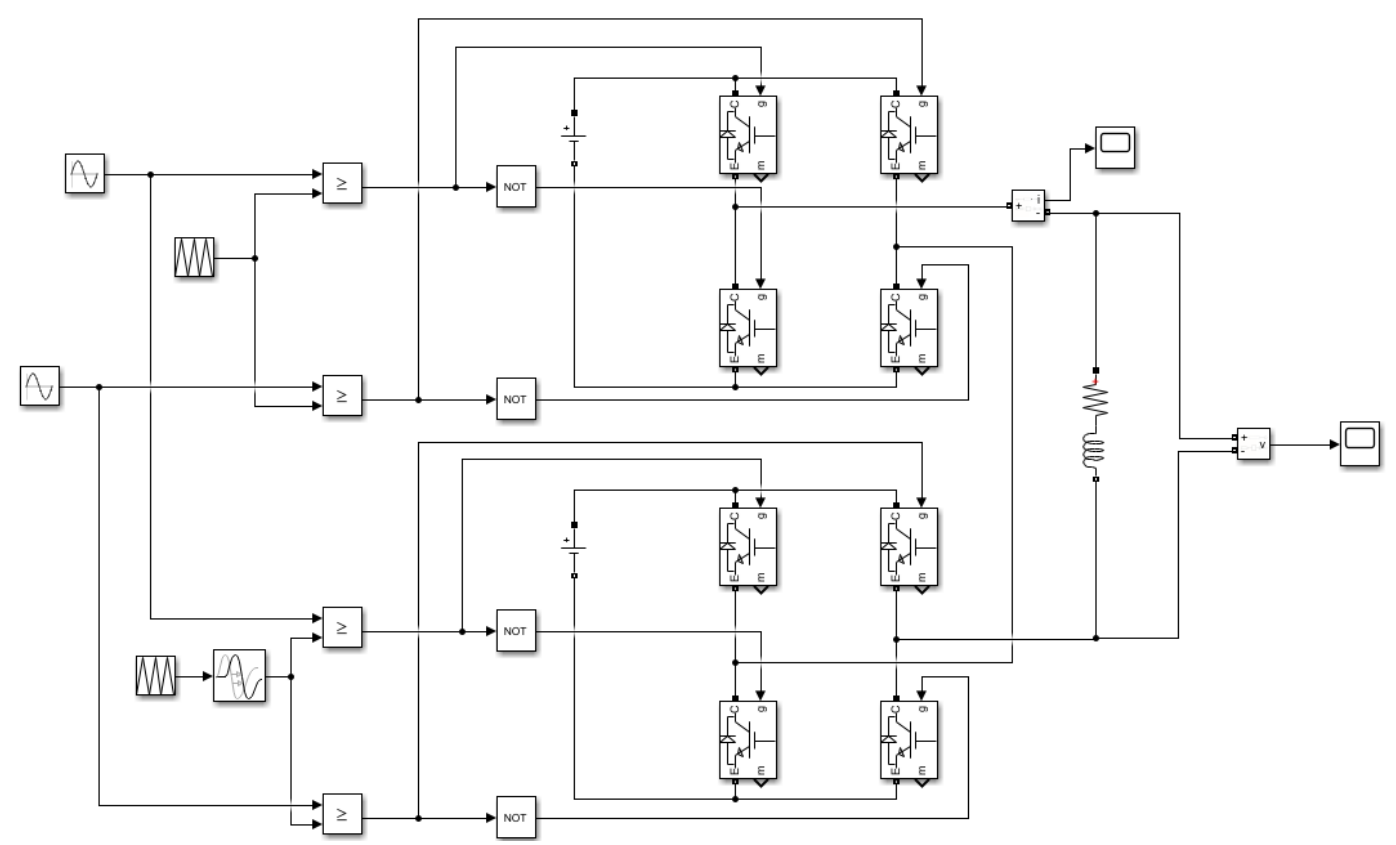

Figure 3 Inverter number 3

All loads were simulated equally, as resistive-inductive loads, for all three inverters. The input voltage was $28 \mathrm{~V}$-DC and output voltage was $115 \mathrm{~V}$-AC, $400 \mathrm{~Hz}$. In Fig. 4 are depicted the waveforms of output current. It could be clearly seen that for inverter number 1 the current waveform is not smooth. This saw-tooth shape is created by not suitable switching method and its harmonic 
components can easily negatively affect the sensitive avionics. On the other hand, the current waveform for inverter number 3 is suitably smoot with reduced higher order harmonic frequency components.
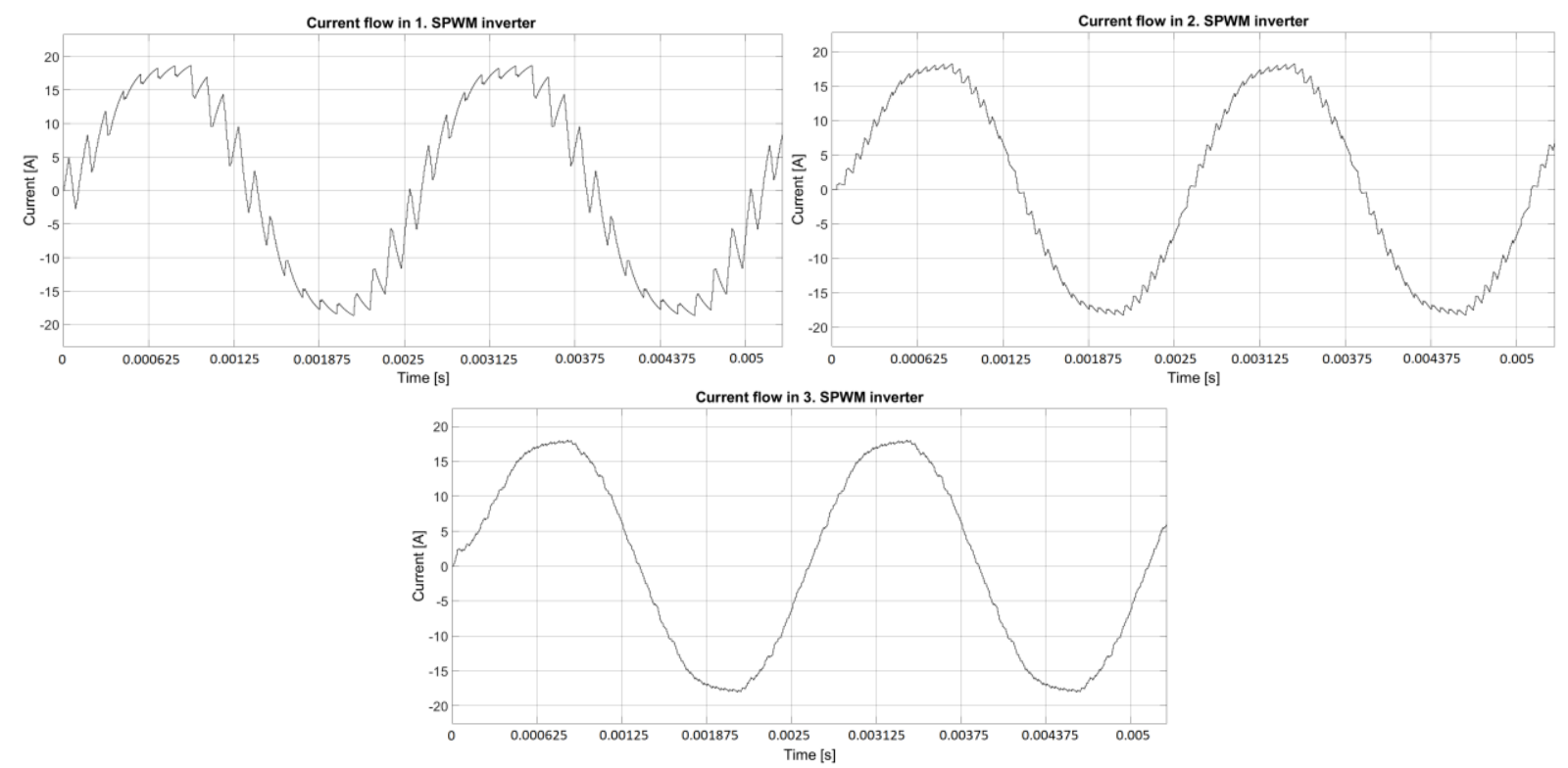

Figure 4 The current output waveforms for a) inventer number 1 b) inverter number 2 c) inverter number 3

\section{CONCLUSION}

Modern aircraft use power converters which use power switches with very rapid switching frequency. This frequency could negatively affect sensitive avionics. Therefore, thorough design of power converter and switching control has to be performed. Suitable power converters use PWM and different switching levels to obtain sinusoidal shape of waveform. Commonly used are the H-Bridge and Buck/Boost converters. For low frequency spectrum the soft switching method has to be implemented for EMI reduction. For high frequency spectrum (several $\mathrm{MHz}$ ) it is necessary to implement EMI filters. The future of aeronautics is in electric propulsion of aircraft. Such a solution will need to implement heavy duty power converters with voltage level of several $\mathrm{kV}$. This will need another thorough research.

\section{References}

[1] Aircraft power conversion. Astronics AES, Business Aircraft, Rotorcraft, and Military. Available at: https://www.astronics.com/product?productgroup=Aircraft Electrical Power Syste ms\&subproduct=aircraft power conversion

[2] Puškáš, T. - Rozenberg, R. Electronic flight bag: In: New Trends in Aviation Development. 2014. Košice.

[3] Adamčík, F. - Schrötter, M. - Češkovič, M. - Leško, J. The Necessity of Decentralized Aircraft Power Distribution System Implementation. In: International Scientific Conference "Modern Safety Technologies in Transportation "(MOSATT 2019)". Košice, 2019.

[4] Adamčík, F. - Schrötter, M. Elektrické systémy lietadiel I. Košice: Technical university of Kosice, Faculty of aeronautics. 2019. 152p.

[5] Moir, I. - Seabridge, A. - Jukes, M. Civil Avionics Systems, 2nd Edition, ed: John Wiley \& Sons. ISBN: 978-1-118-34180-3, 2013. 612p.

[6] Albatran, S. - Smadi, A. I. - Ahmad, H. J. - Koran, A. Online Optimal Switching Frequency Selection for Grid-Connected Voltage Source Inverters: Electronics. 2017. Vol. 6 No. 4. 
[7] Ďurčo, S. - Sabo, S. - Rozenberg, R. - Miženková, Ž. Means of CPDLC using with ATC procedures in terminal maneuvering: In: Distance Learning, Simulation and Communication. 2017. Brno. P. 62-67

[8] Trentin, A - Zanchetta, P - Wheeler, P - Clare, J. Power conversion for a novel AC/DC aircraft electrical distribution system: IET Electrical Systems in Transportation. 2014. Vol. 4. No. 2. P. 29-37

Received 10, 2019, accepted 12,2019

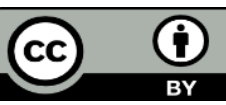

Article is licensed under a Creative Commons Attribution 4.0 International License 